\title{
Vasotocin and isotocin regulate aquaporin 1 function in the sea bream
}

\author{
Juan Antonio Martos-Sitcha1,2,3, Marco Antonio Campinho', Juan Miguel Mancera², \\ Gonzalo Martínez-Rodríguez ${ }^{3}$ and Juan Fuentes ${ }^{1, *}$
}

\begin{abstract}
Aquaporins (AQPs) are specific transmembrane water channels with an important function in water homeostasis. In terrestrial vertebrates, AQP2 function is regulated by vasopressin (AVP) to accomplish key functions in osmoregulation. The endocrine control of aquaporin function in teleosts remains little studied. Therefore, in this study we investigated the regulatory role of vasotocin (AVTR) and isotocin (ITR) receptors in Aqp1 paralog gene function in the teleost gilthead sea bream (Sparus aurata). The complete coding regions of Aqp1a, Aqp1b, AVTR V1a2type, AVTR V2-type and ITR from sea bream were isolated. A Xenopus oocyte-swelling assay was used to functionally characterize AQP1 function and regulation by AVT and IT through their cognate receptors. Microinjection of oocytes with Aqp $1 b$ mRNA revealed regulation of water transport via PKA (IBMX+forskolin sensitive), whereas Aqp1a mRNA injection had the same effect via PKC signaling (PDBU sensitive). In the absence of expressed receptors, AVT and IT $\left(10^{-8} \mathrm{~mol} \mathrm{I}^{-1}\right)$ were unable to modify AQP1 function. AVT regulated AQP1a and AQP1b function only when the AVTR V2-type was coexpressed. IT regulated AQP1 a function, but not AQP1b, only when ITR was present. Considering that Aqp $1 a$ and Aqp $1 b$ gene expression in the sea bream intestine is highly salinity dependent in vivo, our results in ovo demonstrate a regulatory role for AVT and IT in AQP1 function in the sea bream in the processing of intestinal fluid to achieve osmoregulation.
\end{abstract}

KEY WORDS: Aquaporin, Water regulation, Isotocin receptor, Vasotocin receptor, Osmoregulation

\section{INTRODUCTION}

Fish osmoregulation is under endocrine control via specific effects in the osmoregulatory organs, i.e. gills, kidney and gastrointestinal tract (Avella et al., 1999; Gregorio et al., 2013; Laiz-Carrion et al., 2005; Marshall, 2002; Martos-Sitcha et al., 2014, 2013). In hyperosmotic environmental salinities, high amounts of water ingestion (Fuentes and Eddy, 1997) are necessary to compensate for the ionic imbalance in the plasma/external milieu and the dehydrating effect of seawater (Evans et al., 2005; Grosell, 2010). Water absorption at the intestinal level, which appears to be aquaporin (AQP) mediated (Wood and Grosell, 2012), is driven by simultaneous $\mathrm{Cl}^{-}$uptake, mediated by an apical $\mathrm{Na}^{+} / \mathrm{K}^{+} / 2 \mathrm{Cl}^{-}$ (NKCC) co-transporter (Musch et al., 1982) or apical $\mathrm{Cl}^{-} / \mathrm{HCO}_{3}^{-}$ anion exchangers (Grosell, 2006, 2011).

\footnotetext{
${ }^{1}$ Centre of Marine Sciences (CCMar), Universidade do Algarve, Campus de Gambelas, Faro 8005-139, Portugal. ²Departamento de Biología, Facultad de Ciencias del Mar y Ambientales, Universidad de Cádiz, Puerto Real, Cádiz E-11510, Spain. ${ }^{3}$ Instituto de Ciencias Marinas de Andalucía, Consejo Superior Investigaciones Científicas (ICMAN-CSIC), Puerto Real, Cádiz E-11510, Spain.

*Author for correspondence (jfuentes@ualg.pt)
}

Received 24 September 2014; Accepted 15 December 2014
The functions of AQPs are related to water balance between the extracellular and intracellular spaces (Agre et al., 1998, 1999; Preston and Agre, 1991; Preston et al., 1992), tissues and different osmoregulatory organs involved in fluid homeostasis in vertebrates (An et al., 2008; Borgnia et al., 1999; Lignot et al., 2002; Martinez et al., 2005a,b; Nielsen et al., 2002). Currently, 13 AQP families have been described in vertebrates (Agre, et al., 2002; King et al., 2004), which are sub-divided into three different groups depending on their genomic structure and specific function: (i) aquaporin group, (ii) aquaglyceroporin group and (iii) superaquaporin group (Echevarria et al., 1996; Ishibashi et al., 1997, 1998, 2000, 1994; Yang and Verkman, 1997). The aquaporin group is composed of AQP 0, 1, 2, 4, 5, 6 and 8 subtypes (Ishibashi et al., 2000). Not all members of the aquaporin group are represented in fish, which lack AQP2 (Cerdá and Finn, 2010; Finn and Cerdá, 2011). In turn, Aqp 1 expression has been shown in water-permeable tissues such as gills, kidney or intestine (Kwong et al., 2013; Madsen et al., 2014; Martinez et al., 2005a,b; Tipsmark et al., 2010; Raldúa et al., 2008).

The vasopressin (AVP) and oxytocin (OXY) families, including the non-mammalian peptides arginine vasotocin (AVT) and isotocin (IT), have been associated with the regulation of blood pressure and antidiuretic functions in osmoregulation (Amer and Brown, 1995; Henderson and Wales, 1974; Maetz et al., 1964; Moon and Mommsen, 1990; Motais and Maetz, 1967). The endocrine effects of AVT and IT rely on the presence of membrane receptors that mediate the hormonal intrinsic information to carry out their physiological action. AVT and IT receptors (AVTR and ITR) have been cloned in some fish such as the Amargosa pupfish (Cyprinodon variegatus amargosae; Lema, 2010), the African lungfish (Protopterus annectens; Konno et al., 2009) and the gilthead sea bream (Sparus aurata, Martos-Sitcha et al., 2014; Martos-Sitcha et al., 2013). In the last of these, two AVTR types (V1a2-type and V2-type) and a single ITR are expressed in a wide range of organs/tissues, especially in those with an osmoregulatory role.

A functional connection between $\mathrm{AQP} 2$ and the AVP/AVT system demonstrating the involvement of the latter in water channel regulation has been established in terrestrial vertebrates (Agre et al., 2002; Asahina et al., 1995; Fujita et al., 1995; Funayama et al., 2004). For instance, a role for AVP in the on-off regulation of AQP2 mRNA expression has been shown in the collecting duct of rats (Saito et al., 1997). In addition, AQP2 expression is up-regulated by endogenous and exogenous AVP under various pathophysiological conditions (Asahina et al., 1995; Fujita et al., 1995; Fushimi et al., 1993; Hayashi et al., 1994). In teleosts, AQP2 is absent (Cerdá and Finn, 2010; Finn and Cerdá, 2011) and few reports exist to document a functional link between AVT/IT and AQPs. Amongst these is the co-activation of Aqp1 and AVTR (An et al., 2008) induced by hyperosmotic conditions, which is argued to improve the hypo-osmoregulatory ability in the black porgy (Acanthopagrus 
schlegeli). Aqp1 is consistently expressed in the gastrointestinal tract of several fish and is apparently associated with water movements in the intestine (Cerdá and Finn, 2010; Finn and Cerdá, 2011). Additionally, analysis of the sea bream sequences of Aqpla and $A q p 1 b$ detected phosphorylation signals of either protein kinase $\mathrm{C}$ (PKC) or protein kinase A (PKA) (Tingaud-Sequeira et al., 2008) making them accessible to endocrine control. Furthermore, the potential role of AQP and AVTRs in osmoregulatory function, as well as water absorption processes, has been separately studied in the intestine of sea bream (Gregorio et al., 2013; Raldúa et al., 2008). In a recent study (Martos-Sitcha et al., 2013), we have documented a regulatory role of AVT in the intestine of the sea bream via a bumetanide-sensitive mechanism, likely a NKCC cotransporter, which is a regulator of water movements in fish intestine (Musch et al., 1982).

While a functional association between APQs and AVT can be expected in fish, the experimental evidence is mostly circumstantial. Therefore, the present study aimed to explore the putative regulatory role of AVTRs and ITR on Aqpl paralog gene function in the sea bream, $S$. aurata L. using a heterologous expression system, the Xenopus oocyte.

\section{RESULTS}

\section{Aqp1a or Aqp1b in the intestine of sea bream}

The distribution of all genes analyzed by in situ hybridization showed expression in enterocytes of the anterior intestine and rectum of control sea bream (Fig. 1). Intensity wise, Aqpla and Aqp $1 b$ seemed to show complementary expression, with Aqpla mRNA abundance (Fig. 1A and F) higher in the anterior intestine whereas Aqp $1 b$ mRNA (Fig. 1B and G) was more abundant in the rectum. The expression of Aqp la and Aqp $1 b$ was also observed in non-enterocyte cells that resemble fibroblasts (Fig. 1A,B,F,G). In turn, $A V T R V 1 a 2$ signal was abundant in both segments of sea bream intestine (Fig. 1C,H). AVTRV2 expression was present in both intestinal regions (Fig. 1D and I), but its expression was lower in the anterior intestine than in the rectum. ITR expression was present at similar levels in enterocytes of both the anterior intestine (Fig. 1E) and rectum (Fig. 1J).

When analyzed by qPCR, Aqp $1 a$ and Aqp $1 b$ were expressed in the anterior intestine and the rectum of the sea bream gastrointestinal tract (Fig. 2). A decrease in salinity from 37 to 12 ppt increased Aqp la expression in the anterior intestine of fish. However, this effect was not observed in the rectum, where, regardless of external salinity, Aqp la expression remained unchanged (Fig. 2A). The expression of $A q p 1 b$ was severalfold higher in the rectum than in the anterior intestine, regardless of the external salinity. In the anterior intestine, $A q p 1 b$ expression was unaffected by environmental salinity, while higher expression of $A q p 1 b$ was detected in the rectum of fish adapted to hyperosmotic conditions ( 35 and 55 ppt, Fig. 2B).

\section{Aqp expression in oocytes}

Expression of sea bream Aqp1 in Xenopus oocytes was functionally demonstrated by the linear swelling of oocytes in response to a decrease of external osmolality, which was not observed in waterinjected oocytes (Fig. 3). Our results showed that Aqp 1a and Aqp 1b mRNA was translated and the proteins were perfectly functional in the oocyte membrane, as shown by the increase of water permeability values mediated by AQP1a and AQP1b in swelling assays (Fig. 3). In addition, no response was observed in oocytes injected with water alone; therefore, the injected Aqp mRNA functionally mediates the volume increase observed.

\section{Intracellular signaling of AQP1 function}

In oocytes devoid of $A V T R / I T R$ mRNA and expressing only sea bream Aqp la, PKC stimulation (PDBU treatment) increased Pf by about $25 \%$ (Fig. 3A). In contrast, Aqp la expression was insensitive to PKA stimulation by IBMX-FK. The opposite effect was observed in oocytes devoid of $A V T R / I T R$ mRNA and expressing only Aqp $1 b$, where aquaporin function was insensitive to PDBU (PKC stimulation), but responded to IBMX-FK (PKA stimulation, Fig. 3B). $P_{\mathrm{f}}$ in water-injected oocytes was insensitive to PKA stimulation by IBMX-FK or PKC stimulation by PDBU (Fig. 3).
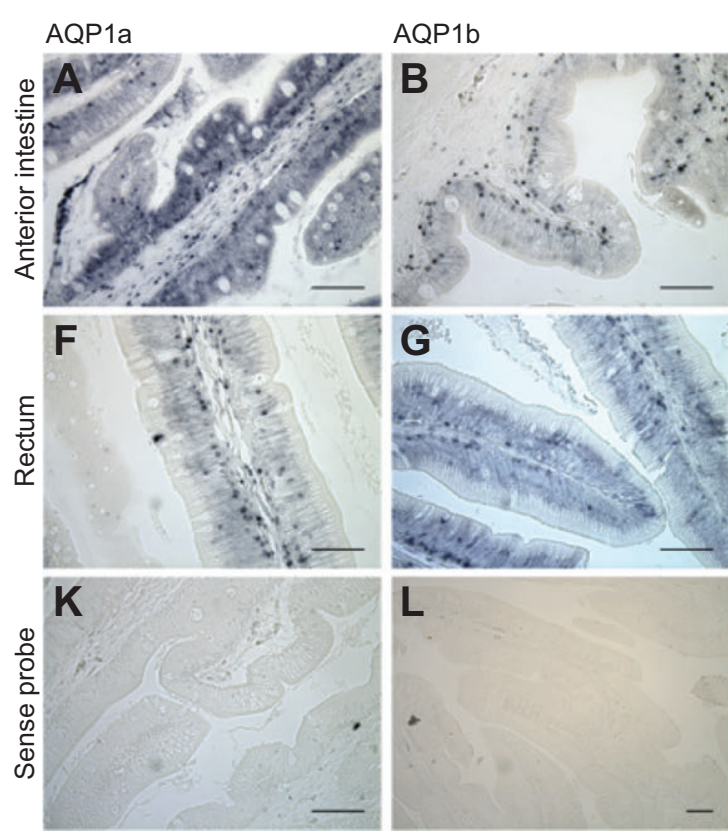

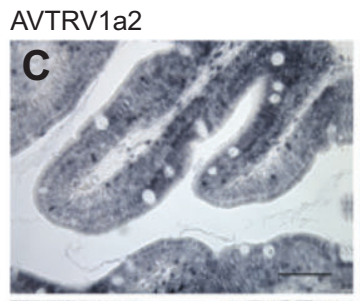

AVTRV2
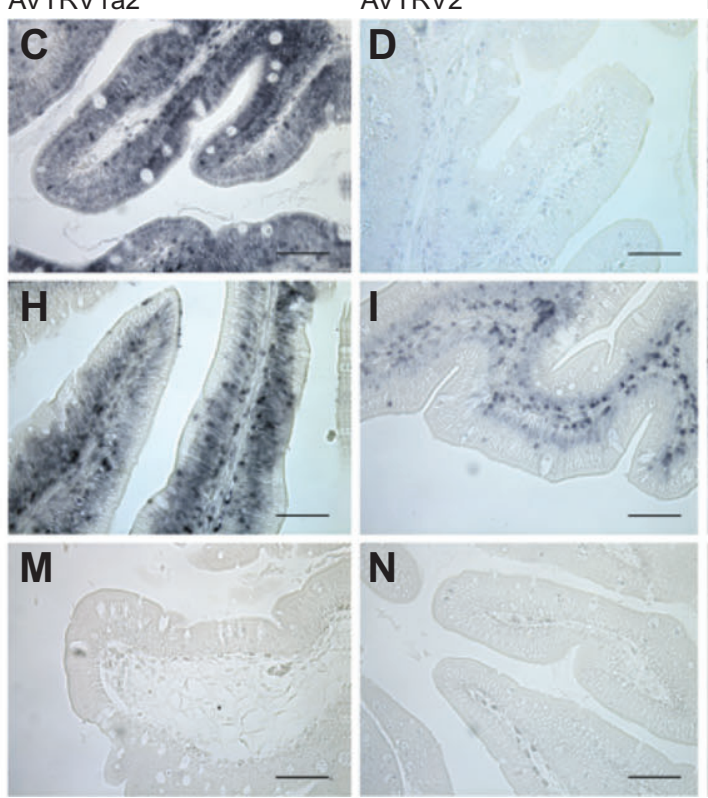

ITR

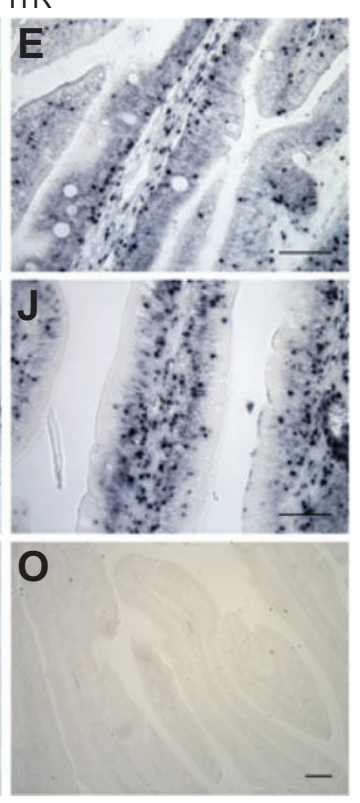

Fig. 1. In situ hybridization of aquaporins, arginine vasotocin receptors and isotocin receptor in the sea bream. In situ hybridization of Aqp1a (A and $\mathrm{F}$ ), Aqp1b (B and G), AVTRV1a2 (C and H), AVTRV2 (D and I) and ITR ( $\mathrm{E}$ and $\mathrm{J}$ ) in the anterior intestine (A-E) and rectum (F-J) of sea bream maintained in $35 \mathrm{ppt}$ seawater. $(\mathrm{K}-\mathrm{O})$ Slides hybridized with a sense probe of each gene analyzed $(\mathrm{K}-\mathrm{M}$, rectum; $\mathrm{N}$ and $\mathrm{O}$, anterior intestine). All scale bars represent $50 \mu \mathrm{m}$. 

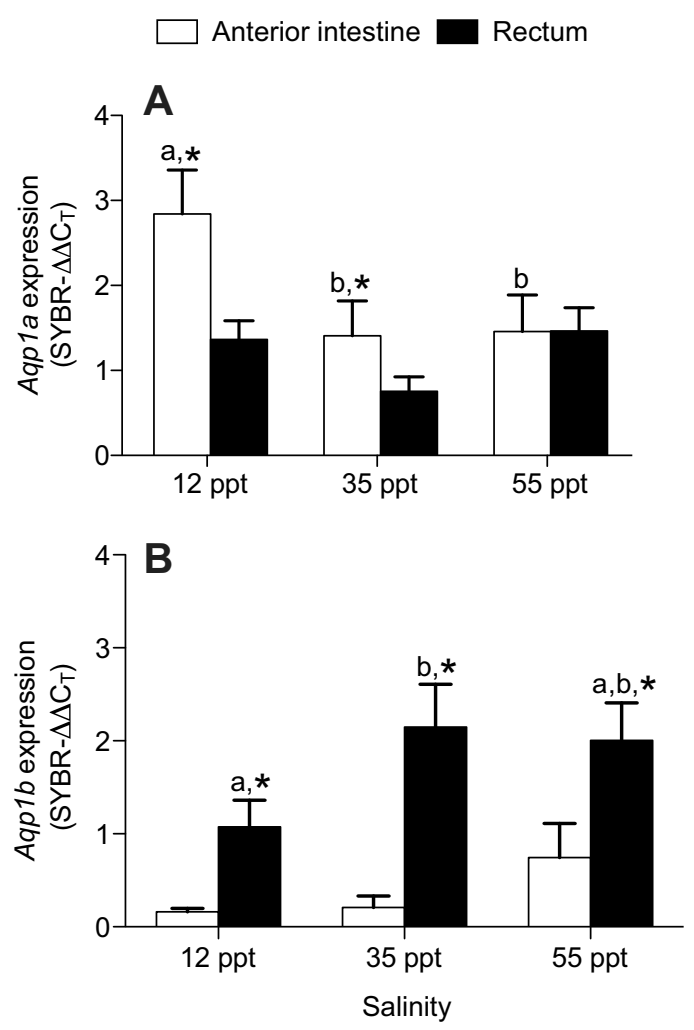

Fig. 2. Relative expression of Aqp1a and Aqp1b in the anterior intestine and the rectum of the sea bream after long-term acclimation to 12, 35 and 55 ppt seawater. (A) Aqp1a, (B) Aqp1b. Results are shown in arbitrary units (SYBR- $\Delta \Delta \mathrm{C}_{\mathrm{T}}$ ) determined by qPCR. Each column represents the mean \pm s.e.m. $(N=7)$. Within a particular intestinal region, bars displaying different letters are significantly different $(P<0.05$, one-way ANOVA followed by Bonferroni post hoc test). Asterisks represent significant differences between intestinal regions at the same salinity $(P<0.05$, Student's $t$-test).

\section{AVT and IT in Aqp1 paralog gene function}

In oocytes devoid of AVTR/ITR mRNA, but expressing either Aqp la (Fig. 4A) or Aqp $1 b$ alone (Fig. 4B), incubation with AVT or IT $\left(10^{-8} \mathrm{~mol}^{-1}\right)$ was without effect on water permeability. This lack of effect to exogenous AVT and IT $\left(10^{-8} \mathrm{moll}^{-1}\right)$ was also observed in water-injected oocytes.

In the absence of hormonal treatment with AVT or IT, coexpression of Aqp 1 a or Aqp 1b with AVTRV1a2, AVTRV2 or ITR was without affect on basal $P_{\mathrm{f}}$ when compared with oocytes injected with either Aqp1a or Aqp1b alone (Figs 4, 5, 6). To test whether AVT or IT modified $P_{\mathrm{f}}$ via AQP1a or AQP1b, a typical doseresponse with 100 -fold increments between $10^{-12}$ and $10^{-6} \mathrm{~mol} \mathrm{l}^{-1}$ was tested for each AQP-receptor combination (Figs 5 and 6). AQP1a function (expressed as changes in $P_{\mathrm{f}}$ ) was unaffected by AVT treatment when its mRNA was co-expressed with AVTRV1a2 mRNA (Fig. 5A,B). In contrast, co-expression of Aqpla mRNA with either AVTRV2 or ITR mRNA produced a typical doseresponse increase of $P_{\mathrm{f}}$ following stimulation with AVT or IT, respectively (Fig. 5). In both cases, the calculated $\mathrm{EC}_{50}$ was $10^{-9.8} \mathrm{~mol}^{-1}$ (Fig. 5). The AVT/IT effect was robust even after $300 \mathrm{~s}$ and the response to the hormone was immediate (Fig. 5).

In the case of AQP1b, incubation with AVT significantly enhanced water permeability only when co-expressed with the AVTR V2-type (Fig. 6D,E,F). The effect conformed to a typical dose-response curve with a calculated $\mathrm{EC}_{50}$ of $10^{-9.9} \mathrm{~mol} \mathrm{l}^{-1}$
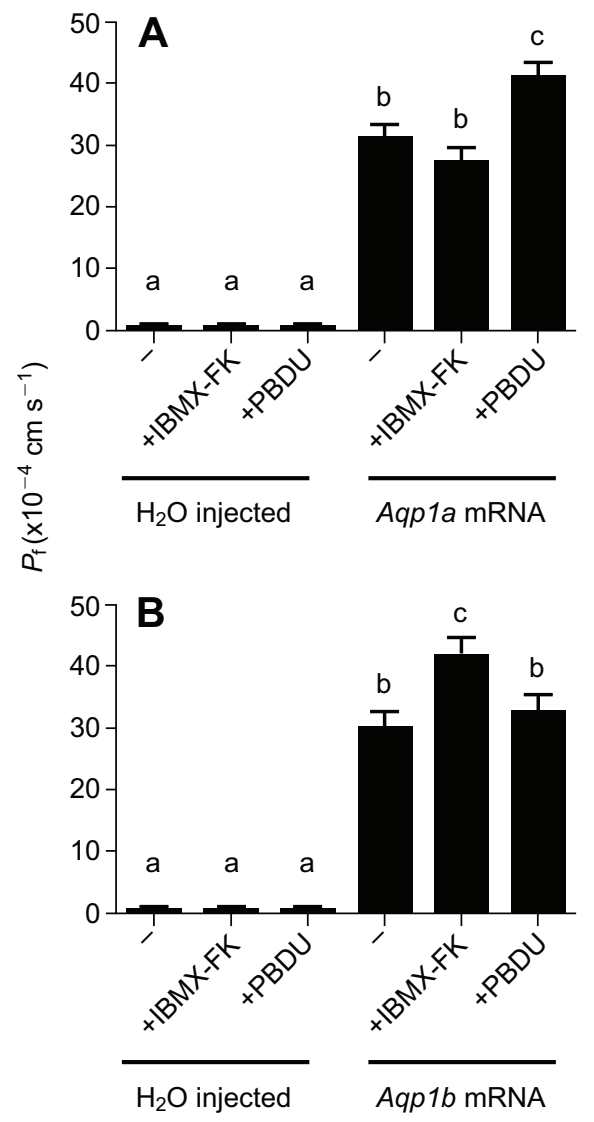

Fig. 3. Osmotic water permeability $\left(P_{\mathrm{f}}\right)$ in Xenopus laevis oocytes expressing Aqp1a or Aqp1b in response to IBMX-FK or PDBU. (A) Aqp1a, (B) Aqp1b. + IBMX-FK indicates the presence of $100 \mu \mathrm{mol} \mathrm{I}^{-1}$ IBMX+ $10 \mu \mathrm{mol} \mathrm{I} \mathrm{I}^{-1} \mathrm{FK}$; +PDBU indicates the presence of $2 \mu \mathrm{mol} \mathrm{I} \mathrm{I}^{-1} \mathrm{PDBU} ;-$, no treatment. Each bar represents the mean \pm s.e.m. of 20-25 oocytes from three different animals. Groups displaying different letters are significantly different $(P<0.05$, one-way ANOVA followed by Bonferroni post hoc test).

(Fig. 6F). Additionally, co-expression of Aqplb with either AVTRVIa2 or ITR mRNA was without effect on oocyte swelling when the receptors were stimulated with their corresponding hormones (Fig. 6).

\section{DISCUSSION}

In the present study, we established the functional regulation of AQP1 homologs by AVT and IT via specific receptors in the sea bream. These findings reinforce the importance of the AVT/AVP system in AQP-mediated water balance in vertebrates (Mahlmann et al., 1994; Mordasini et al., 2005; Schafer et al., 1990; Warne, 2001; Warne et al., 2002).

mRNA expression of Aqp1 paralogs, i.e. Aqp $1 a$ and Aqp 1b, was identified in different portions of the sea bream intestine (Raldúa et al., 2008). In vivo effects of external salinity on aquaporin expression in the intestine and in particular the anterior intestine and the rectum further highlight the clear functional specialization in intestinal fluid processing (ion and water transport) previously demonstrated in the sea bream (Gregorio et al., 2013; Martos-Sitcha et al., 2013). This is in agreement with Aqp la mRNA levels in the anterior intestine, as well as higher Aqp $1 b$ expression in the rectum, previously reported for the sea bream (Raldúa et al., 2008).

The complementary pattern of Aqp mRNA expression in the intestine, also described in Atlantic salmon (Tipsmark et al., 2010), 

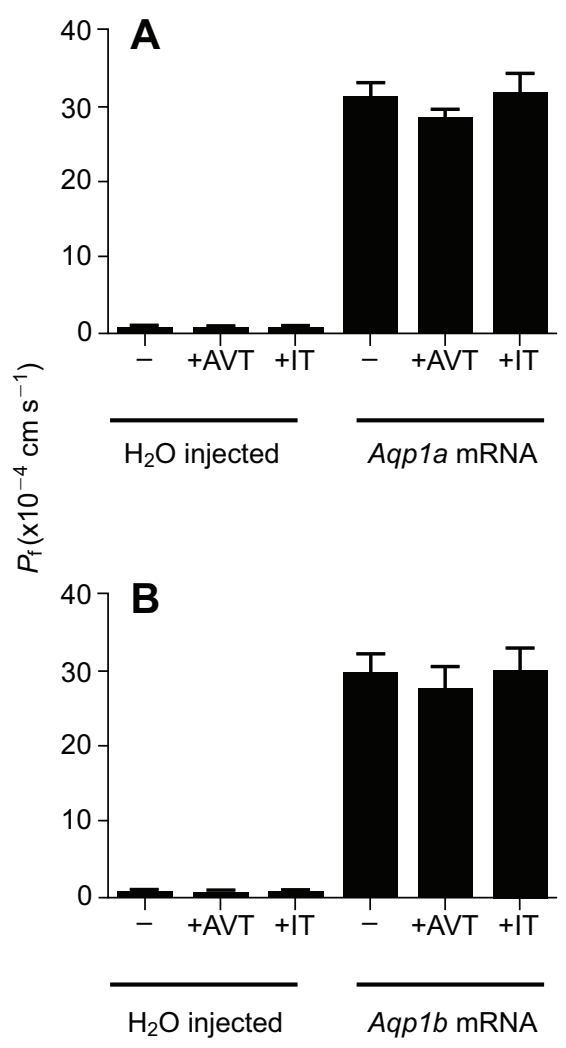

Fig. 4. Osmotic water permeability $\left(P_{\mathrm{f}}\right)$ in $X$. laevis oocytes expressing Aqp1a or Aqp1b in response to AVT or IT. +AVT, $10^{-8} \mathrm{~mol} \mathrm{I}^{-1}$ AVT; +IT, $10^{-8} \mathrm{~mol} \mathrm{I}^{-1} \mathrm{IT} ;-$, no ligand. Each bar represents the mean \pm s.e.m. of 20-25 oocytes from three different animals. No significant differences due to the presence of hormones were observed in water-injected or Aqp-injected oocytes $(P<0.05$, one-way ANOVA followed by Bonferroni post hoc test).

may reveal a functional overlap/complementation between the two Aqp 1 paralog genes in the anterior and posterior intestine, at least in the sea bream. These observations, based on mRNA expression alone, are in good agreement with the minor absolute effect of salinity on water absorption in the anterior intestine of salinitychallenged sea bream (Gregorio et al., 2013), whereas increasing water absorption in the rectum of sea bream challenged with $55 \mathrm{ppt}$ (Gregorio et al., 2013) may be mostly mediated by AQP1b action. Taking into account the presence of AVTR V2-type and ITR in both intestinal regions (Martos-Sitcha et al., 2013, 2014), two main factors could determine the functional importance of the regulatory action of AVT and IT on AQP1 function in sea bream: firstly, the relative distribution/abundance of Aqpl homologs in the intestinal tract; and secondly, the availability of receptor ligand(s) in the plasma, which is also salinity dependent (Martos-Sitcha et al., 2013).

To understand how AVT and IT systems may regulate AQP1 function in sea bream, we employed a swelling assay in Xenopus oocytes. This assay has been used to characterize different AQPs because of their large size and the lack of endogenous water channels in the membrane (Agre et al., 1999). In fact, the expression of wildtype Aqp genes has previously been demonstrated to increase water $P_{\mathrm{f}}$ values in Xenopus oocytes (Fushimi et al., 1997, 1994, 1993; Kuwahara et al., 1995; Yang and Verkman, 1997). AVT and IT receptors have recently been cloned in different teleost species, including the sea bream, and are considered to be relevant elements in osmoregulation (Konno et al., 2009; Lema, 2010; Martos-Sitcha et al., 2013). These receptors achieve the biological actions of the ligands via intracellular second-messenger pathways. The regulation of AQP function can be achieved via different signaling pathways (Dibas et al., 1998). AVTR/AVPR V1a-type and ITR were shown to act via PKC, which uses phospholipase C (PLC), inositol-1,4,5trisphosphate (IP3) or $\mathrm{Ca}^{2+}$ intracellular signaling pathways (Wargent et al., 1999). In contrast, PKA, whose activity is dependent on cellular levels of cyclic AMP (cAMP), is preferentially used by AVT/AVP V2-type receptors (Wargent et al., 1999; Warne, 2001). Although direct phosphorylation of AQPs was not demonstrated in this study, we have shown that sea bream Aqpla-mediated water transport is positively regulated by PKC but not PKA signaling, whereas the opposite holds true for Aqp1b (Fig. 3). This shows that AQP1 function is regulated by phosphorylation, which might constitute a rapid response mechanism to osmoregulatory challenges. This feature of sea bream AQP1 contrasts with human AQP1, which is insensitive to direct stimulation with cAMP, but instead resembles human AQP2 (Tsunoda et al., 2004). Strikingly, the fact that sea bream Aqpla and $A q p 1 b$ are specifically stimulated via different intracellular signaling pathways further highlights sub-functionalization of these paralog genes.

The Xenopus oocyte heterologous system has already been used for neuropeptide receptor characterization (Akhundova et al., 1996; Hausmann et al., 1995; Kimura et al., 1992; Mahlmann et al., 1994; Sugimoto et al., 1994). However, to our knowledge, characterization of the interaction between AVTR and ITR with AQP function has not been carried out, in spite of the conceivable co-regulation suggested by other authors in in vivo studies (An et al., 2008; Hatakeyama et al., 2001; Konno et al., 2010). Here, we suggest a selective and physiologically specific effect of this approach to study AQP function and regulation. AVT and IT alone were unable to stimulate function in Aqp mRNA-only injected oocytes. Such stimulation was only possible when Aqp mRNA was co-injected with specific AVTR or ITR $\mathrm{mRNA}$ and in the presence of their cognate hormone, demonstrating a non-genomic correlation of AVT/IT with aquaporin function. These results show that in the assay there are no endogenous AVT or IT receptors and that the effects observed in our assay are highly specific for each AQP-receptor-hormone combination. However, AVTR V1a2-type did not regulate either AQP1a or AQP1b function, even in the presence of AVT (Figs 5 and 6). This result is unexpected, considering that the intracellular pathway preferentially used by this receptor, i.e. $\mathrm{PKC}$, is active in oocytes and enhanced $P_{\mathrm{f}}$ in AQP1a alone (Fig. 3). This suggests that PKC signaling might regulate $\mathrm{AQP} 1 \mathrm{a}$ function via other hormones/ receptors or independently of hormonal regulation. In contrast, AVT stimulation of oocyte swelling, mediated by AQP1a or AQP1b, occurs only when the AVTR V2-type receptor is present (Figs 5 and 6). More importantly, the significant hormonal effects on swelling were achieved at $10^{-8} \mathrm{~mol} \mathrm{l}^{-1}$ AVT, which is within the physiological range of circulating AVT in sea bream plasma (Kleszczynska et al., 2006; Mancera et al., 2008) and at the level observed for AVT actions in ion transport in ex vivo experiments in sea bream intestine (MartosSitcha et al., 2013). Additionally, based on AQP sensitivity (Fig. 3), the effect mediated by AVT V2-type receptors on both AQP1a and AQP1b function would involve stimulation of PKA and perhaps PKC. It is unsurprising that AQP1a is regulated by AVTRV2 given that PKA is the preferential signaling pathway associated with this receptor, and PKC signaling seems to play a minor role (Wargent et al., 1999; Warne, 2001). However, previous studies in frog demonstrated the V2-type receptor could also function via stimulation of PLC pathways, one of the alternative pathways for PKC (Acharjee et al., 2004; Zhu et al., 1994). Further studies will be required to establish whether 


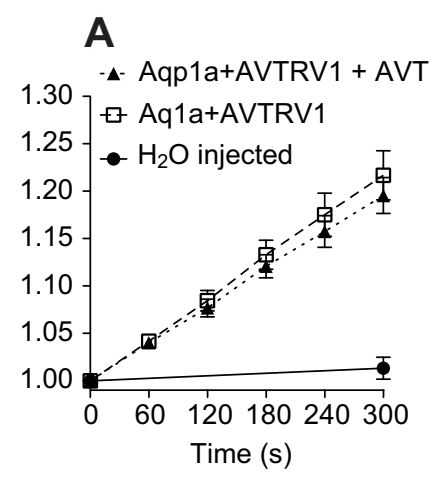

D

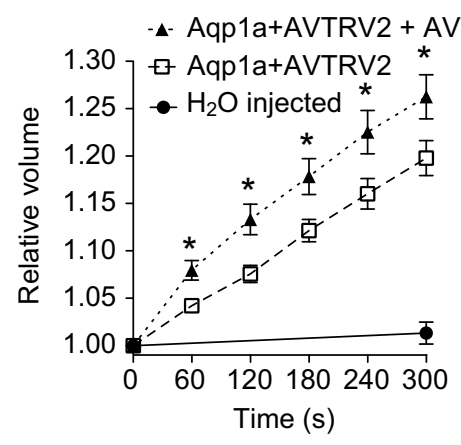

G

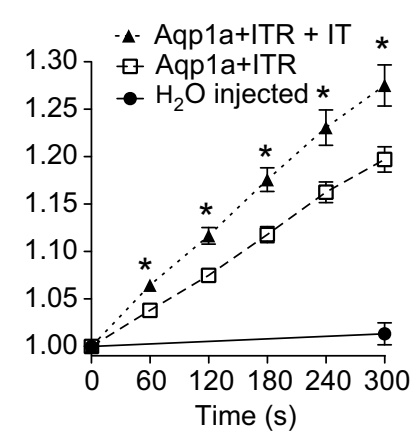

B

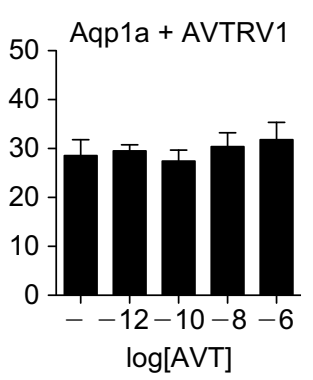

E

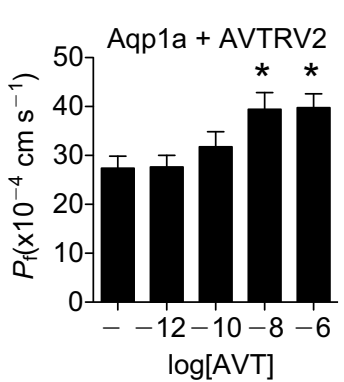

H

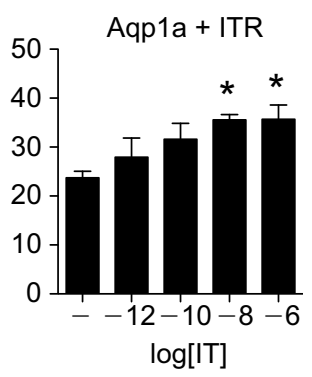

C

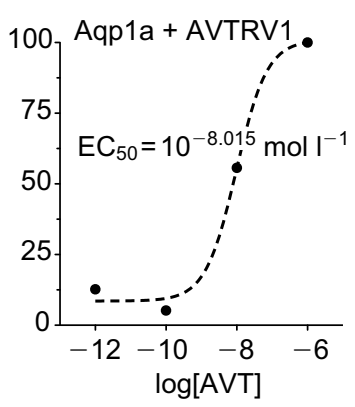

$\mathbf{F}$

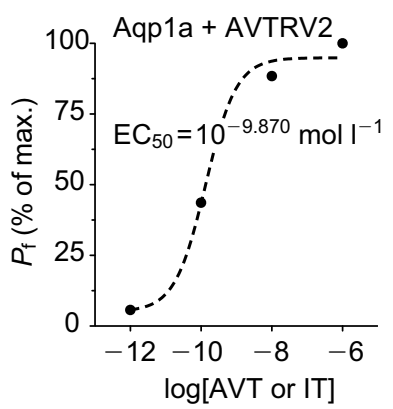

I

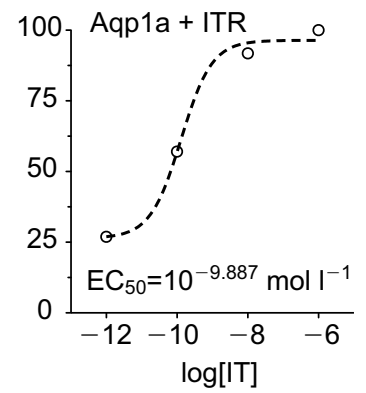

Fig. 5. Relative volume increase and $P_{\mathrm{f}}$ of $X$. laevis oocytes co-injected with Aqp1a and AVTRV1, Aqp1a and AVTRV2, or Aqp1a and ITR mRNA, with or without stimulation with AVT or IT. $(A, D, G)$ Relative volume increase following coinjection with Aqp1a and AVTRV1 (A), Aqp1a and AVTRV2 (D) or Aqp1a and ITR (G) mRNA with or without stimulation with $10^{-8} \mathrm{~mol} I^{-1}$ AVT $(A, D)$ or $10^{-8} \mathrm{~mol} \mathrm{I}^{-1} \mathrm{IT}(\mathrm{G})$. Water-injected oocytes were used as controls. In A, D and G, asterisks represent a significantly different increase in relative volume in the presence or absence of hormone $(P<0.05$, ANCOVA). (B,E,H) The corresponding doseresponse relationships of osmotic water permeability $\left(P_{\mathrm{f}}\right)$ in response to hormonal stimulation in the range $10^{-12}$ to $10^{-6} \mathrm{~mol} \mathrm{I}^{-1}$. In $\mathrm{B}, \mathrm{E}$ and $\mathrm{H}$, asterisks represent significant differences from basal $P_{\mathrm{f}}(P<0.05$, one-way ANOVA followed by Bonferroni post hoc test). (C,F,I) The adjusted sigmoidal dose-response curves (from $B, E$ and $H$, respectively) for calculation of individual $\mathrm{EC}_{50}$ values depicted in each graph. sea bream AVT V2-type receptors could also function via PKC signaling.

The isotocinergic system has been proposed to play endocrine roles related to reproductive stage, social status and behavior in teleosts (Almeida et al., 2012; Kleszczynska et al., 2012). The role of IT in the osmoregulatory process is not well established, and sometimes seems dubious because of the lack of predictable plasma levels of the hormone (Hyodo and Urano, 1991; Kleszczynska et al., 2006; Warne et al., 2000). In osmoregulatory tissues, IT receptor expression responds to osmotic challenges in several species of teleosts, including the sea bream (Martos-Sitcha et al., 2013). However, other studies in vitro suggest an indirect osmoregulatory role of copeptin, a peptide derived from an IT precursor, via pituitary stimulation of prolactin expression (Flores et al., 2007). Our present results also suggest a function for IT in water balance via functional regulation of AQP1a, but not AQP1b, in sea bream (Figs 5 and 6). Significant up-regulation of sea bream AQP1a function by IT was achieved at concentrations of $10^{-8} \mathrm{~mol} \mathrm{l}^{-1}$, with a calculated $\mathrm{EC}_{50}$ of $10^{-9.8} \mathrm{~mol}^{-1}$ (Fig. 5). These values give physiological meaning to the regulation of AQP1a by IT, considering that circulating plasma levels of the hormone in the sea bream are in the range $1-180 \mathrm{nmol}^{-1}$ (Kleszczynska et al., 2006;
Mancera et al., 2008). Additionally, AQP1a is sensitive to PKC stimulation (Fig. 3), but not to PKA stimulation, as proposed for the ITR in teleosts (Hausmann et al., 1995).

In conclusion, the present study provides an indication of a functional involvement of AVT and IT in the regulation of water transport via AQP1 paralogs in the sea bream. The (likely) most important target of this regulation relates to regional salinitydependent fluid processing in the gastrointestinal system, and maybe other epithelia. The levels at which exogenous AVT and IT regulate AQP-dependent water transport were in the normal physiological range for sea bream plasma (Kleszczynska et al., 2006; Mancera et al., 2008), pointing to a physiological role of both hormones in vivo. Additionally, only AVTRV2 and ITR were able to modulate AQP1 function in oocyte swelling assays. However, it will be important to establish how (or whether) this putative regulatory correlation in replicated in a sea bream intestinal cell in vivo.

\section{MATERIALS AND METHODS}

\section{Peptides and chemicals}

Arginine vasotocin ([ $\left.\mathrm{Arg}^{8}\right]$-vasotocin acetate), isotocin ([Ser $\left.{ }^{4}, \mathrm{Il}^{8}\right]-$ oxytocin), forskolin (FK), 3-isobutyl-1-methylxanthine (IBMX) and 


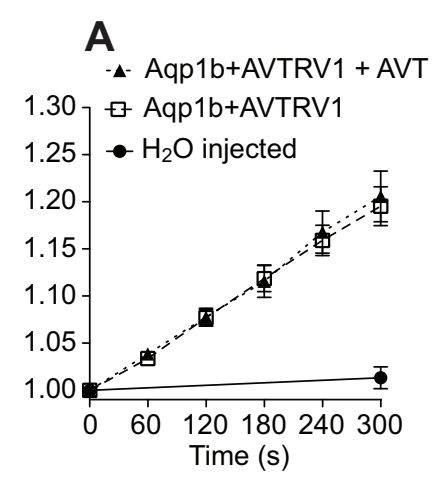

\section{B}

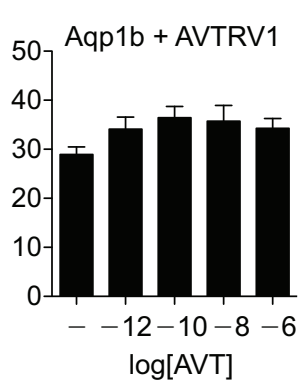

E

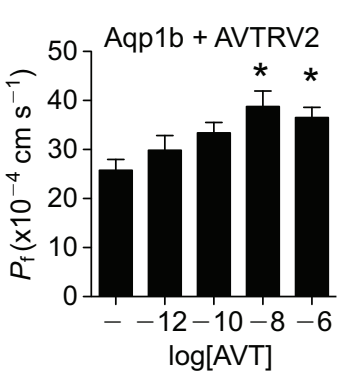

H

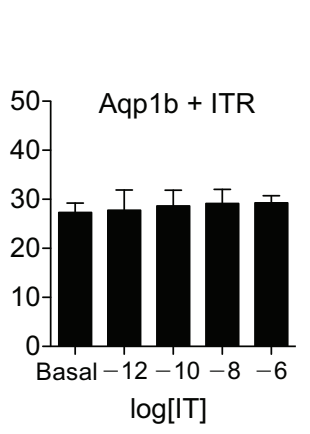

C

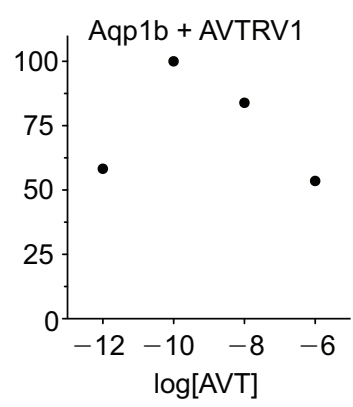

$\mathbf{F}$

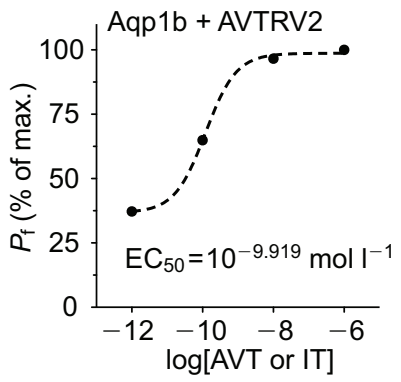

I

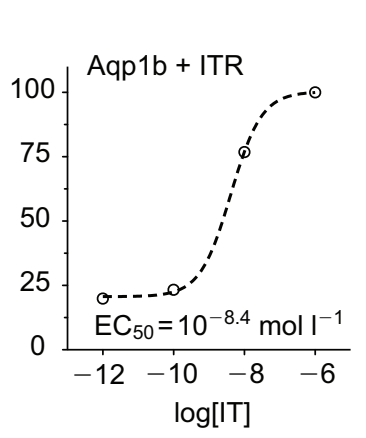

Fig. 6. Relative volume increase and $P_{\mathrm{f}}$ of $X$. laevis oocytes co-injected with Aqp1b and AVTRV1, Aqp1b and AVTRV2, or Aqp1b and ITR mRNA, with or without stimulation with AVT or IT. $(A, D, G)$ Relative volume increase following co-injection with Aqp1b and AVTRV1 (A), Aqp $1 b$ and AVTRV2 (D) or Aqp1b and ITR (G) mRNA with or without stimulation with $10^{-8} \mathrm{~mol} \mathrm{I}^{-1}$ AVT $(A, D)$ or $10^{-8} \mathrm{~mol} \mathrm{I}^{-1}$ IT (G). Water-injected oocytes were used as controls. In $A, D$ and $G$, asterisks represent a significantly different increase in relative volume in the presence or absence of hormone $(P<0.05$, ANCOVA). (B,E,H) The corresponding doseresponse relationships of osmotic water permeability $\left(P_{\mathrm{f}}\right)$ in response to hormonal In $\mathrm{B}, \mathrm{E}$ and $\mathrm{H}$, asterisks represent significant differences from basal $P_{\mathrm{f}}(P<0.05$, one-way ANOVA followed by Bonferroni post hoc test). $(C, F, I)$ The adjusted sigmoidal dose-response curves (from $B, E$ and $H$, respectively) whenever possible for calculation of individual $\mathrm{EC}_{50}$ values depicted in each graph. stimulation in the range $10^{-12}$ to $10^{-6} \mathrm{~mol} \mathrm{I}^{-1}$

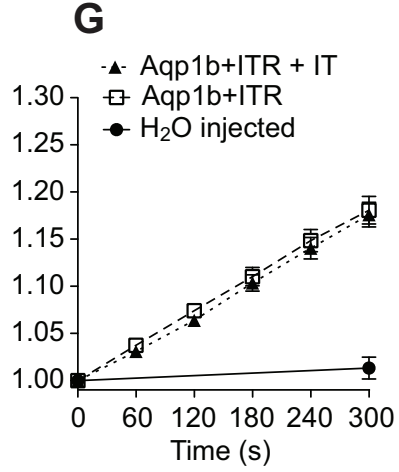

phorbol 12,13-dibutyrate (PDBU) were of the highest grade and were supplied by Sigma-Aldrich (Madrid, Spain).

\section{Animals}

Sea bream (S. aurata) juveniles were obtained from commercial sources (CUPIMAR SA, Cádiz, Spain) and maintained in open-seawater circuits under natural conditions of water temperature $\left(18-20^{\circ} \mathrm{C}\right)$, photoperiod and salinity ( $37 \mathrm{ppt}$ ) at a density of $<5 \mathrm{~kg} \mathrm{~m}^{-3}$. For maintenance, fish were fed twice daily to a final ration of $2 \%$ of body mass, with a commercial sea bream diet (Trow España SA, Cojóbar, Burgos, Spain). All fish were fasted for $24 \mathrm{~h}$ before experimental manipulations.

Sexually mature female Xenopus laevis were obtained from commercial sources (Xenopus Express, France), maintained at $18^{\circ} \mathrm{C}$ in 601 tanks and fed daily.

All animal manipulations were carried out in compliance with the Guidelines of the European Union Council (86/609/EU) and Portuguese legislation for the use of laboratory animals. All animal protocols were performed under a Group-1 license from the Direcção-Geral de Veterinária, Ministerio da Agricultura, do Desenvolvimento Rural e das Pescas, Portugal.

\section{Aqp 1 and AVTRIITR constructs}

For tissue collection, sea bream (body mass $250 \mathrm{~g}$, immature males) were anesthetized (2-phenoxyethanol 1:10,000; Sigma-Aldrich). After decapitation, samples from the anterior intestine, which corresponds to a section of $2-2.5 \mathrm{~cm}$ in length caudal to the point of insertion of the pyloric caeca, were collected from individual fish, kept overnight in RNALater (Ambion, Austin, TX, USA) at $4{ }^{\circ} \mathrm{C}$ and stored at $-20^{\circ} \mathrm{C}$ until utilized for RNA extraction (within 2 weeks). Total RNA was isolated using the E.Z.N.A. Total RNA Kit (OMEGA Bio-tek, Norcross, GA, USA) following the manufacturer's instructions, and the quantity and quality assessed (Nanodrop 1000, Thermo Scientific, Barrington, IL, USA). RNA was treated with DNase using a DNA-free kit (Ambion, Life Technologies, Paisley, UK); 500 ng total RNA were reverse transcribed (RevertAid ${ }^{\mathrm{TM}}$ First Strand cDNA Synthesis Kit, no. K1622, Fermentas, Thermo Scientific) and PCR amplifications were carried out with $200 \mathrm{ng}$ of cDNA with iProof ${ }^{\mathrm{TM}}$ High-Fidelity DNA Polymerase (Bio-Rad, Hercules, CA, USA) with the following protocols: $98^{\circ} \mathrm{C}, 4 \mathrm{~min} ;\left[98^{\circ} \mathrm{C}, 15 \mathrm{~s} ; 60^{\circ} \mathrm{C}, 15 \mathrm{~s} ; 72^{\circ} \mathrm{C}, 1 \mathrm{~min}\right] \times 35$ cycles; $72^{\circ} \mathrm{C}, 10 \mathrm{~min}$ ) for Aqpla (GenBank accession number: AY626939), Aqp1b (accession no. AY626938), AVTRV1a2 (accession no. KC195974), AVTRV2 (accession no. KC960488) and ITR (accession no. KC195973). Primers used for amplification are shown in Table 1. For identity confirmation, PCR products were ligated to $\mathrm{pGEM}$ T-easy vector (PROMEGA, Madison, WI, USA) and sequenced in both directions (CCMar, Faro, Portugal).

\section{Aqp1a and Aqp1b distribution in the sea bream intestine} In situ hybridization

Sea bream (body mass $200 \mathrm{~g}$, immature males, $N=3$ ) kept at $35 \mathrm{ppt}$ were anesthetized (2-phenoxyethanol 1:10,000) and killed by decapitation. The 
Table 1. Primers used for molecular identification of open reading frames (ORFs) of the Aqp1a, Aqp1b, AVTRV1a2, AVTRV2 and ITR sequences

\begin{tabular}{|c|c|}
\hline & Nucleotide sequence $\left(5^{\prime}-3^{\prime}\right)$ \\
\hline \multicolumn{2}{|l|}{ UTR primers } \\
\hline Aqp1a-Fw & CACAGCCAGACAGCAACACTGC \\
\hline Aqp1a-Rv & TTAAGTCTGTGTGGGACTATTTTG \\
\hline Aqp1b-Fw & GGTTTGACACACCGAACACATTCG \\
\hline Aqp1b-Rv & GCTTAAGTCTGTGTGGGATCAGTGC \\
\hline AVTR V1-type Fw & GGTCTCTGGTTTTCAGTCC \\
\hline AVTR V1-type Rv & CTGTGAGCTGTGTACCTTGATG \\
\hline AVTR V2-type Fw & AGGACACGCGTGAGAAAGCTTACC \\
\hline AVTR V2-type RV & ACTGTGTGTCATTCTCTGTCGC \\
\hline ITR Fw & GACTCTTGTGTTGTGATGTGACCG \\
\hline ITR Rv & ATTGCCAGGTTACTCAACTACAGG \\
\hline \multicolumn{2}{|l|}{ ORF primers } \\
\hline EcoRI-Aqp1a-Fw & CCGGAATTCATGAGAGAGTTCAAGA \\
\hline Xbal-Aqp1a-Rv & $\begin{array}{l}\text { GCAAGCTAG } \overline{T C T A G A C T A T T T T G A C G T C} \\
\text { ATCTCTACAGC }\end{array}$ \\
\hline EcoRl-Aqp1b-Fw & CCGGAATTCATGACAGAAGTAAAAA \\
\hline Xbal-Aqp1b-Rv & $\begin{array}{l}\text { GCTGGCTAGTCTAGATCAGTGCTTTGGC } \\
\text { CACTGACTTGG }\end{array}$ \\
\hline A-V1-type Fw & AATGGGAACCCCTGGAAACGAC \\
\hline Xbal-V1-type Rv & $\begin{array}{l}\text { CTAGTCTAGACTAGCTGTGATTTTCCTCC } \\
\text { GGCTG }\end{array}$ \\
\hline EcoRI-V2-type Fw & CCGGAATTCATGGAAAGCATCAGTTTGG \\
\hline Xbal-V2-type Rv & CTAGTCTAGATCAGTACAGGCTGTCCTTGG \\
\hline EcoRI-ITR Fw & CCGGAATTCATGGAGGACTTTTTACGCGA \\
\hline Xbal-ITR Rv & $\begin{array}{l}\text { GCTAGTCTAGATCAGTGTCCAAGTCCCCCC } \\
\text { GTGCT }\end{array}$ \\
\hline
\end{tabular}

Restrictions sites are in italics and underlined. Additional nucleotides added for maintaining the ORF are in bold italics and underlined.

UTR, untranslated region.

anterior intestine and rectum were collected from individual fish, washed and fixed in $4 \% \mathrm{PFA} / 1 \times \mathrm{PBS} \mathrm{pH} 7$ overnight at $4{ }^{\circ} \mathrm{C}$. The following day the tissues were washed in $1 \times$ PBS $+0.1 \%$ Tween-20 (Sigma; PBT) and stored at $-20^{\circ} \mathrm{C}$ in methanol until use (within 3 days). Tissues were embedded in paraffin as described elsewhere (Campinho et al., 2012) and serial $5 \mu \mathrm{m}$ sections were cut and set on glass slides.

In situ hybridization sense and anti-sense cRNA DIG-labeled probes for Aqp1a, Aqp1b, AVTRV1a2, AVTRV2 and ITR were generated by in vitro transcription using SP6 or T7 (Fermentas), respectively, according to the manufacturer's instructions. In situ hybridization analysis was carried out as described elsewhere (Campinho et al., 2012). All slides for the same gene analyzed were processed in parallel. Images were taken in a Leica DM2000 light microscope coupled to a Leica DFC480 digital camera. Scale bars were added to images in ImageJ (Schindelin et al., 2012) and figures assembled in Photoshop (Adobe).

\section{qPCR}

For Aqp $1 a$ and Aqp $1 b$ expression analysis, the same experimental protocol previously described (Gregorio et al., 2013; Martos-Sitcha et al., 2013) was used. In short, juvenile sea bream ( $N=21 ; 20-30 \mathrm{~g}$ body mass) were kept at different salinities $(12,35$ or $55 \mathrm{ppt})$ for 2 months before tissue collection and were considered fully adapted (Laiz-Carrion et al., 2005). Fish were fed normally during the trial and no mortality was registered.

Total RNA was isolated and cDNA was produced as described above. Real-time PCR (qPCR) amplifications were performed in duplicate in a final volume of $10 \mu$ l with $5 \mu 1$ PerfeCTa SYBR ${ }^{\circledR}$ Green FastMix ${ }^{\mathrm{TM}}$ (Quanta BioSciences), 0.5 pmol $\mu 1^{-1}$ of each forward and reverse primer, and $200 \mathrm{ng}$ cDNA. qPCR was performed with the following cycling conditions: $95^{\circ} \mathrm{C}, 10 \mathrm{~min} ;\left[95^{\circ} \mathrm{C}, 20 \mathrm{~s} ; 60^{\circ} \mathrm{C}, 35 \mathrm{~s}\right]$ for 45 cycles. Melting curves for all analyzed genes were performed from $60^{\circ} \mathrm{C}$ to $95^{\circ} \mathrm{C}$ with stepping intervals of $15 \mathrm{~s}$. 18S ribosomal RNA (18S) was used as an internal standard. All calibration curves exhibited correlation coefficients $R^{2}>0.98$, and the corresponding real-time PCR efficiencies were $>99 \%$.
Table 2. Primer sequences $\left(5^{\prime}\right.$ to $\left.3^{\prime}\right)$, PCR amplicon size (bp) and corresponding NCBI accession numbers used for qPCR expression analysis of Aqp1a, Aqp1b and 18S

\begin{tabular}{llll}
\hline Primer & Sequence & Amplicon & Accession no. \\
\hline qAqp1a-Fw & GGCTCTCACGTACGATTTCC & 153 & AY626939 \\
qAqp1a-Rv & TCTGTGTGGGACTATTTTGACG & & \\
qAqp1b-Fw & GCGACGGAGTGATGTCAAAGG & 203 & AY626938 \\
qAqp1b-Rv & AGATAAGAGCCGCCGCTATGC & & \\
$18 S$ Fw & AACCAGACAAATCGCTCCAC & 139 & AY993930 \\
$18 S \mathrm{Rv}$ & CCTGCGGCTTAATTTGACTC & & \\
\hline
\end{tabular}

Relative gene quantification was performed using the $\Delta \Delta \mathrm{C}_{\mathrm{T}}$ method (Livak and Schmittgen, 2001). Primers used for $\mathrm{qPCR}$ are shown in Table 2.

\section{Expression vectors and capped mRNA production}

A PCR was run using the pGEM T-easy vectors containing the specific sequences as templates, and the same PCR program as described above. Specific restriction enzyme digestion sites were included in the primer sequences used and the open reading frames of the fusion proteins were maintained (Table 1). Amplified PCR products, as well as pCS2+ were double-digested for $2 \mathrm{~h}$ at $37^{\circ} \mathrm{C}$ with $X b a \mathrm{I}$ and EcoRI (FastDigest, Fermentas, Thermo Scientific) and fragments of interest were separated in agarose gel and purified (GeneJET Gel extraction kit, Fermentas, Thermo Scientific). Digested products were cloned into pCS2+, amplified, purified and sequenced to confirm correct assembly of the constructs.

For capped mRNA production, $5 \mu \mathrm{g}$ of each expression vector was linearized with Not $\mathrm{I}$ (FastDigest, Fermentas, Thermo Scientific) for $2 \mathrm{~h}$ at $37^{\circ} \mathrm{C}$ and precipitated overnight at $-20^{\circ} \mathrm{C}$ using 0.1 volumes of sodium acetate $\left(3 \mathrm{~mol} \mathrm{l}^{-1}\right)$ and 2.5 volumes of $100 \%$ ethanol. The linearized DNA template was centrifuged and cleaned twice with $70 \%$ ethanol then resuspended in nuclease-free water. DNA purity and concentration were obtained spectrophotometrically (Nanodrop 1000, Thermo Scientific). In vitro capped messenger RNA (cRNA) synthesis was carried out from $1 \mu \mathrm{g}$ of linearized vector using the mMESSAGE mMACHINE ${ }^{\circledR}$ SP6 kit (Ambion, Life Technologies) for $2 \mathrm{~h}$ at $37^{\circ} \mathrm{C}$. At the end of the in vitro transcription reaction, the remaining DNA was digested with TURBO ${ }^{\mathrm{TM}}$ DNase. Transcribed mRNA was phenol-chloroform purified and precipitated as described above then resuspended in $\mathrm{H}_{2} \mathrm{O}$. The integrity and expected size of each mRNA reaction was examined by electrophoresis, the quantity was assessed (Nanodrop 1000), and it was aliquoted and stored at $-80^{\circ} \mathrm{C}$ until use.

\section{Oocyte isolation, microinjection and swelling assay}

For ovary collection, sexually mature female $X$. laevis were anesthetized with neutralized benzocaine $\left(250 \mathrm{mg}^{-1}\right)$ and killed by decapitation. Both ovaries were removed and kept in sterile MBS solution $\left(88 \mathrm{mmol}^{-1} \mathrm{NaCl}\right.$, $1 \mathrm{mmol} 1^{-1} \mathrm{KCl}, 2.5 \mathrm{mmol}^{-1} \mathrm{NaHCO}_{3}, 5 \mathrm{mmol} 1^{-1}$ Hepes, pH 7.6). For oocyte defolliculation, the ovary was manually disaggregated in small lumps and transferred to sterile $\mathrm{Ca}^{2+}$-free ND96 solution $\left(96 \mathrm{mmol} \mathrm{l}^{-1}\right.$ $\mathrm{NaCl}, 2 \mathrm{mmol} \mathrm{l}^{-1} \mathrm{KCl}, 1 \mathrm{mmol} \mathrm{l}^{-1} \mathrm{MgCl}_{2}, 5 \mathrm{mmol} \mathrm{l}^{-1}$ Hepes, $\mathrm{pH}$ 7.6) containing type Ia collagenase ( $1 \mathrm{mg} \mathrm{m}^{-1}$, Sigma-Aldrich) for $1.5-2 \mathrm{~h}$ with gentle agitation. After defolliculation, oocytes were individualized, and washed three times in $\mathrm{Ca}^{2+}$-free ND96 solution, three times in ND96 solution containing $1.8 \mathrm{mmol}^{-1} \mathrm{CaCl}_{2}$ and three times with NDE (ND96 containing $2.5 \mathrm{mmol}^{-1}$ pyruvate, $10 \mu \mathrm{g} \mathrm{ml}^{-1}$ streptomycin, $100 \mathrm{U} \mathrm{ml}^{-1}$ penicillin, $\mathrm{pH}$ 7.6). Oocytes in stages $\mathrm{V}$ and VI were identified under the stereomicroscope and maintained in NDE at $18^{\circ} \mathrm{C}$ until use (within 3 days of isolation) with daily medium changes.

Twenty-four hours after defolliculation, oocytes received a single microinjection (Nanoliter 2000, World Precision Instruments, Sarasota, FL, USA) of $50 \mathrm{nl}$ of water with $10 \mathrm{ng}$ of each cRNA in the following combinations: (1) no cRNA $\left(\mathrm{H}_{2} \mathrm{O}\right.$ injected control); (2) Aqp la; (3) Aqp lb; (4) Aqp1a+AVTRV1a2; (5) Aqp1a+AVTRV2; (5) Aqp1a+ITR; (7) Aqp1b+ AVTRV1a2; (8) Aqp1b+AVTRV2; and (9) Aqp1b+ITR. 
Swelling assays were carried out 3 days post-injection in all the tested combinations. Swelling was produced by a change in osmolality $(\Delta \mathrm{Osm})$ of $180 \mathrm{mOsm}$; standard NDE $=201.00 \pm 1.73 \mathrm{mOsm} \mathrm{kg}^{-1} ; \mathrm{NDE}_{\text {swelling }}=21.66 \pm$ $1.20 \mathrm{mOsm} \mathrm{kg}^{-1}$ (Vapro 5520 osmometer Wescor, USA). The osmotic water permeability coefficient $\left(P_{\mathrm{f}}, \mathrm{cm} \mathrm{s}^{-1}\right)$ of each oocyte was calculated from the oocyte surface area $\left(S, \mathrm{~cm}^{2}\right)$, initial oocyte volume $\left(V_{0}, \mathrm{~cm}^{3}\right)$, molar volume of water $\left(v_{\mathrm{w}}=18 \mathrm{~cm}^{3} \mathrm{~mol}^{-1}\right)$ and the initial rate of oocyte swelling $\left[\mathrm{d}\left(V / V_{0}\right) / \mathrm{d} t, \mathrm{~s}^{-1}\right]$, according to the expression (Agre et al., 1999):

$$
P_{\mathrm{f}}=V_{0} \cdot\left[\mathrm{d}\left(\left[V / V_{0}\right]\right) / \mathrm{d} t\right] /\left(S \cdot v_{\mathrm{w}} \cdot \Delta \text { Osm }\right),
$$

where $P_{\mathrm{f}}$ is $10^{-4} \mathrm{~cm} \mathrm{~s}^{-1}$. Oocyte volume (assuming the shape of a perfect sphere) and surface area were calculated from images captured at timed intervals up to $5 \mathrm{~min}$ with a digital camera (Visicam 10.0, VWR, Portugal) attached to a stereomicroscope (SZ-60 Olympus). According to this general method, the following sub-assays were performed: (1) sensitivity of AQP1a and AQP1b to PKA (with a combination of $100 \mu \mathrm{mol} 1^{-1}$ IBMX and $\left.10 \mu \mathrm{mol} 1^{-1} \mathrm{FK}\right)$ or PKC $\left(2 \mu \mathrm{mol} 1^{-1}\right.$ PDBU $)$; (2) effect of AVT or IT $\left(10^{-8} \mathrm{~mol}^{-1}\right)$ on AQP1a and AQP1b functionality in oocytes devoid of sea bream receptors; and (3) water permeability in oocytes co-expressing Aqp la or $A q p 1 b$ together with $A V T R V 1 a 2, A V T R V 2$ or IRT in response to hormonal stimulation.

To cover the range of circulating plasma values in the sea bream (Kleszczynska et al., 2006; Mancera et al., 2008) for both hormones, swelling assays were performed in the absence (basal group) or presence of AVT (AVTR V1a2-type, AVTR V2-type) or IT (ITR) receptors at concentrations of $10^{-12}, 10^{-10}, 10^{-8}$ or $10^{-6} \mathrm{~mol} 1^{-1}$. For hormonal/ pharmacological manipulations, oocytes were pre-incubated for $15 \mathrm{~min}$ in the presence of the agent, which was also present during the swelling assay in diluted medium ( $\mathrm{NDE}_{\text {swelling }}$ )

\section{Statistics}

Results are presented as means \pm s.e.m. All statistics were performed after assessing homogeneity of variance and normality. Expression analysis of aquaporins was assessed with a two-way analysis of variance (ANOVA), considering intestinal region and external salinity as main factors. As the interaction between both factors was highly significant $(P<0.001)$, subsequent statistical analysis of the data was carried out using, as appropriate, Student's $t$-test (intestinal region) and one-way ANOVA followed by the post hoc Bonferroni test (salinity). Analysis of covariance (ANCOVA) was used to compare regression lines in swelling assays by studying the interaction of the categorical variable (presence of hormone) with the continuous independent variable (time). In those cases where a regulatory action of hormones on aquaporin function was significant, $P_{\mathrm{f}}$ values were used for calculation of individual $\mathrm{EC}_{50}$ values $\left(\mathrm{mol} \mathrm{l}^{-1}\right)$ and adjusted to sigmoid curves. All statistical analyses were performed with Prism 5.0 (GraphPad Prism 5.0 for Macintosh, GraphPad Software, San Diego, CA, USA) and groups were considered significantly different at $P<0.05$.

\section{Competing interests}

The authors declare no competing or financial interests.

\section{Author contributions}

J.F. conceived the study. J.A.M.-S., M.A.C. and J.F. performed the experiments. J.A. M.-S. and J.F. drafted the manuscript. J.A.M.-S., M.A.C., J.M.M., G.M.-R. and J.F. wrote the paper.

\section{Funding}

J.A.M.-S. received support from the Ministry of Education (FPU AP2008-01194, Spain), M.A.C. received post-doctoral support from the Portuguese National Science Foundation [SFRH/BPD/66808/2009]. The study was funded by Ministry of Science and Education, Spain by Project AGL2010-14876 to J.M.M. and the National Science Foundation (FCT, Portugal) Project PTDC/MAR-BIO/3811/2012 to J.F.

\section{References}

Acharjee, S., Do-Rego, J. L., Oh, D. Y., Moon, J. S., Ahn, R. S., Lee, K., Bai, D. G., Vaudry, H., Kwon, H. B. and Seong, J. Y. (2004). Molecular cloning, pharmacological characterization, and histochemical distribution of frog vasotocin and mesotocin receptors. J. Mol. Endocrinol. 33, 293-313.
Agre, P., Bonhivers, M. and Borgnia, M. J. (1998). The aquaporins, blueprints for cellular plumbing systems. J. Biol. Chem. 273, 14659-14662.

Agre, P., Mathai, J. C., Smith, B. L. and Preston, G. M. (1999). Functional analyses of aquaporin water channel proteins. Methods Enzymol. 294, 550-572.

Agre, P., King, L. S., Yasui, M., Guggino, W. B., Ottersen, O. P., Fujiyoshi, Y. Engel, A. and Nielsen, S. (2002). Aquaporin water channels-from atomic structure to clinical medicine. J. Physiol. 542, 3-16.

Akhundova, A., Getmanova, E., Gorbulev, V., Carnazzi, E., Eggena, P. and Fahrenholz, F. (1996). Cloning and functional characterization of the amphibian mesotocin receptor, a member of the oxytocin/vasopressin receptor superfamily. Eur. J. Biochem. 237, 759-767.

Almeida, O., Gozdowska, M., Kulczykowska, E. and Oliveira, R. F. (2012). Brain levels of arginine-vasotocin and isotocin in dominant and subordinate males of a cichlid fish. Horm. Behav. 61, 212-217.

Amer, S. and Brown, J. A. (1995). Glomerular actions of arginine vasotocin in the in situ perfused trout kidney. Am. J. Physiol. 269, R775-R780.

An, K. W., Kim, N. N. and Choi, C. Y. (2008). Cloning and expression of aquaporin 1 and arginine vasotocin receptor mRNA from the black porgy, Acanthopagrus schlegeli: effect of freshwater acclimation. Fish Physiol. Biochem. 34, 185-194.

Asahina, Y., Izumi, N., Enomoto, N., Sasaki, S., Fushimi, K., Marumo, F. and Sato, C. (1995). Increased gene expression of water channel in cirrhotic rat kidneys. Hepatology 21, 169-173.

Avella, M., Pärt, P. and Ehrenfeld, J. (1999). Regulation of $\mathrm{Cl}^{-}$secretion in seawater fish (Dicentrarchus labrax) gill respiratory cells in primary culture. J. Physiol. 516, 353-363.

Borgnia, M., Nielsen, S., Engel, A. and Agre, P. (1999). Cellular and molecular biology of the aquaporin water channels. Annu. Rev. Biochem. 68, 425-458.

Campinho, M. A., Galay-Burgos, M., Silva, N., Costa, R. A., Alves, R. N., Sweeney, G. E. and Power, D. M. (2012). Molecular and cellular changes in skin and muscle during metamorphosis of Atlantic halibut (Hippoglossus hippoglossus) are accompanied by changes in deiodinases expression. Cell Tissue Res. 350, 333-346.

Cerdà, J. and Finn, R. N. (2010). Piscine aquaporins: an overview of recent advances. J. Exp. Zool. A Ecol. Genet. Physiol. 313, 623-650.

Dibas, A. I., Mia, A. J. and Yorio, T. (1998). Aquaporins (water channels): role in vasopressin-activated water transport. Exp. Biol. Med. 219, 183-199.

Echevarria, M., Windhager, E. E. and Frindt, G. (1996). Selectivity of the renal collecting duct water channel aquaporin-3. J. Biol. Chem. 271, 25079-25082.

Evans, D. H., Piermarini, P. M. and Choe, K. P. (2005). The multifunctional fish gill: dominant site of gas exchange, osmoregulation, acid-base regulation, and excretion of nitrogenous waste. Physiol. Rev. 85, 97-177.

Finn, R. N. and Cerdà, J. (2011). Aquaporin evolution in fishes. Front. Physiol. 2, 44

Flores, C. M., Muñoz, D., Soto, M., Kausel, G., Romero, A. and Figueroa, J. (2007). Copeptin, derived from isotocin precursor, is a probable prolactin releasing factor in carp. Gen. Comp. Endocrinol. 150, 343-354.

Fuentes, J. and Eddy, F. B. (1997). Drinking in marine, euryhaline and freshwater teleost fish. In Ionic Regulation in Animals (ed. N. Hazon, F. B. Eddy and G. Flik), pp. 135-149. Heidelberg: Springer-Verlag.

Fujita, N., Ishikawa, S. E., Sasaki, S., Fujisawa, G., Fushimi, K., Marumo, F. and Saito, T. (1995). Role of water channel AQP-CD in water retention in SIADH and cirrhotic rats. Am. J. Physiol. 269, F926-F931.

Funayama, H., Nakamura, T., Saito, T., Yoshimura, A., Saito, M., Kawakami, M. and Ishikawa, S.-E. (2004). Urinary excretion of aquaporin-2 water channe exaggerated dependent upon vasopressin in congestive heart failure. Kidney Int 66, 1387-1392.

Fushimi, K., Uchida, S., Harat, Y., Hirata, Y., Marumo, F. and Sasaki, S. (1993) Cloning and expression of apical membrane water channel of rat kidney collecting tubule. Nature 361, 549-552.

Fushimi, K., Sasaki, S., Yamamoto, T., Hayashi, M., Furukawa, T., Uchida, S. Kuwahara, M., Ishibashi, K., Kawasaki, M., Kihara, I. et al. (1994). Functional characterization and cell immunolocalization of AQP-CD water channel in kidney collecting duct. Am. J. Physiol. 267, F573-F582.

Fushimi, K., Sasaki, S. and Marumo, F. (1997). Phosphorylation of serine 256 is required for CAMP-dependent regulatory exocytosis of the aquaporin-2 wate channel. J. Biol. Chem. 272, 14800-14804.

Gregorio, S. F., Carvalho, E. S. M., Encarnacao, S., Wilson, J. M., Power, D. M., Canario, A. V. M. and Fuentes, J. (2013). Adaptation to different salinities exposes functional specialization in the intestine of the sea bream (Sparus aurata L.). J. Exp. Biol. 216, 470-479.

Grosell, M. (2006). Intestinal anion exchange in marine fish osmoregulation. J. Exp. Biol. 209, 2813-2827.

Grosell, M. (2010). The role of the gastrointestinal tract in salt and water balance. In Fish Physiology. Vol. 30. The Multifunctional Gut of Fish (ed. M. Grosell, T. Farrell and C. Brauner), pp. 135-164. London: Academic Press.

Grosell, M. (2011). Intestinal anion exchange in marine teleosts is involved in osmoregulation and contributes to the oceanic inorganic carbon cycle. Acta Physiol. 202, 421-434. 
Hatakeyama, S., Yoshida, Y., Tani, T., Koyama, Y., Nihei, K., Ohshiro, K. Kamiie, J.-I., Yaoita, E., Suda, T., Hatakeyama, K. et al. (2001). Cloning of a new aquaporin (AQP10) abundantly expressed in duodenum and jejunum. Biochem. Biophys. Res. Commun. 287, 814-819.

Hausmann, H., Meyerhof, W., Zwiers, H., Lederis, K. and Richter, D. (1995) Teleost isotocin receptor: structure, functional expression, mRNA distribution and phylogeny. FEBS Lett. 370, 227-230.

Hayashi, M., Sasaki, S., Tsuganezawa, H., Monkawa, T., Kitajima, W., Konishi, K., Fushimi, K., Marumo, F. and Saruta, T. (1994). Expression and distribution of aquaporin of collecting duct are regulated by vasopressin V2 receptor in rat kidney. J. Clin. Invest. 94, 1778-1783.

Henderson, I. W. and Wales, N. A. M. (1974). Renal diuresis after injections of the freshwater eel and antidiuresis arginine vasotocin in (Anguilla anguilla L.) J. Endocrinol. 61, 487-500.

Hyodo, S. and Urano, A. (1991). Changes in expression of provasotocin and proisotocin genes during adaptation to hyper- and hypo-osmotic environments in rainbow trout. J. Comp. Physiol. B 161, 549-556.

Ishibashi, K., Sasaki, S., Fushimi, K., Uchida, S., Kuwahara, M., Saito, H., Furukawa, T., Nakajima, K., Yamaguchi, Y., Gojobori, T. et al. (1994). Molecular cloning and expression of a member of the aquaporin family with permeability to glycerol and urea in addition to water expressed at the basolateral membrane of kidney collecting duct cells. Proc. Natl. Acad. Sci. USA 91 6269-6273.

Ishibashi, K., Kuwahara, M., Gu, Y., Kageyama, Y., Tohsaka, A., Suzuki, F., Marumo, F. and Sasaki, S. (1997). Cloning and functional expression of a new water channel abundantly expressed in the testis permeable to water, glycerol, and urea. J. Biol. Chem. 272, 20782-20786.

Ishibashi, K., Kuwahara, M., Gu, Y., Tanaka, Y., Marumo, F. and Sasaki, S. (1998). Cloning and functional expression of a new aquaporin (AQP9) abundantly expressed in the peripheral leukocytes permeable to water and urea, but not to glycerol. Biochem. Biophys. Res. Commun. 244, 268-274.

Ishibashi, K., Kuwahara, M., Kageyama, Y., Sasaki, S., Susuki, M. and Imai, M. (2000). Molecular cloning of a new aquaporin superfamily in mammals. In Molecular Biology and Physiology of Water and Solute Transport (ed. S. Hohmann and S. Neilsen), pp 123-126. New York; London: Kluwer Academic/ Plenum Publishers.

Kimura, T., Tanizawa, O., Mori, K., Brownstein, M. J. and Okayama, H. (1992). Structure and expression of a human oxytocin receptor. Nature 356 526-529.

King, L. S., Kozono, D. and Agre, P. (2004). From structure to disease: the evolving tale of aquaporin biology. Nat. Rev. Mol. Cell Biol. 5, 687-698.

Kleszczyńska, A., Vargas-Chacoff, L., Gozdowska, M., Kalamarz, H., MartínezRodríguez, G., Mancera, J. M. and Kulczykowska, E. (2006). Arginine vasotocin, isotocin and melatonin responses following acclimation of gilthead sea bream (Sparus aurata) to different environmental salinities. Comp. Bichem. Physiol. A Mol. Integr. Physiol. 145, 268-273.

Kleszczyńska, A., Sokołowska, E. and Kulczykowska, E. (2012). Variation in brain arginine vasotocin (AVT) and isotocin (IT) levels with reproductive stage and social status in males of three-spined stickleback (Gasterosteus aculeatus). Gen. Comp. Endocrinol. 175, 290-296.

Konno, N., Hyodo, S., Yamaguchi, Y., Kaiya, H., Miyazato, M., Matsuda, K. and Uchiyama, M. (2009). African lungfish, Protopterus annectens, possess an arginine vasotocin receptor homologous to the tetrapod V2-type receptor. J. Exp. Biol. 212, 2183-2193.

Konno, N., Hyodo, S., Yamaguchi, Y., Matsuda, K. and Uchiyama, M. (2010). Vasotocin/V2-type receptor/aquaporin axis exists in African lungfish kidney but is functional only in terrestrial condition. Endocrinology 151 1089-1096.

Kuwahara, M., Fushimi, K., Terada, Y., Bai, L., Marumo, F. and Sasaki, S. (1995) cAMP-dependent phosphorylation stimulates water permeability of aquaporincollecting duct water channel protein expressed in Xenopus oocytes. J. Biol. Chem. 270, 10384-10387.

Kwong, R. W. M, Kumai, Y. and Perry, S. F. (2013). The role of aquaporin and tight junction proteins in the regulation of water movement in larval zebrafish (Danio rerio). PLoS ONE 8, e70764.

Laiz-Carrión, R., Guerreiro, P. M., Fuentes, J., Canario, A. V. M., Del Río, M. P. M. and Mancera, J. M. (2005). Branchial osmoregulatory response to salinity in the gilthead sea bream, Sparus auratus. J. Exp. Zool. A Comp. Exp. Biol. 303A 563-576

Lema, S. C. (2010). Identification of multiple vasotocin receptor cDNAs in teleos fish: sequences, phylogenetic analysis, sites of expression, and regulation in the hypothalamus and gill in response to hyperosmotic challenge. Mol. Cell. Endocrinol. 321, 215-230.

Lignot, J. H., Cutler, C. P., Hazon, N. and Cramb, G. (2002). Water transport and aquaporins in the European eel (Anguilla anguilla). Symp. Soc. Exp. Biol. 54, 49-59.

Livak, K. J. and Schmittgen, T. D. (2001). Analysis of relative gene expression data using real-time quantitative PCR and the 2(-Delta Delta C(T)) method. Methods 25, 402-408
Madsen, S. S., Bujak, J. and Tipsmark, C. K. (2014). Aquaporin expression in the Japanese medaka (Oryzias latipes, Temminck \& Schlegel) in FW and SW: challenging the paradigm of intestinal water transport? J. Exp. Biol. 217, 3108-3121.

Maetz, J., Bourguet, J., Lahlough, B. and Hourdry, J. (1964). [Neurohypophysial peptides and osmoregulation in Carassius auratus]. Gen. Comp. Endocrinol. 4 508-522.

Mahlmann, S., Meyerhof, W., Hausmann, H., Heierhorst, J., Schonrock, C. Zwiers, H., Lederis, K. and Richter, D. (1994). Structure, function, and phylogeny of [Arg8]vasotocin receptors from teleost fish and toad. Proc. Natl. Acad. Sci. USA 91, 1342-1345.

Mancera, J. M., Vargas-Chacoff, L., García-López, A., Kleszczyńska, A., Kalamarz, H., Martínez-Rodríguez, G. and Kulczykowska, E. (2008). High density and food deprivation affect arginine vasotocin, isotocin and melatonin in gilthead sea bream (Sparus auratus). Comp. Biochem. Physiol. A Mol. Integr Physiol. 149, 92-97.

Marshall, W. S. (2002). $\mathrm{Na}^{+}, \mathrm{Cl}^{-}, \mathrm{Ca}^{2+}$ and $\mathrm{Zn}^{2+}$ transport by fish gills: retrospective review and prospective synthesis. J. Exp. Zool. 293, 264-283.

Martinez, A.-S., Cutler, C. P., Wilson, G. D., Phillips, C., Hazon, N. and Cramb, G. (2005a). Cloning and expression of three aquaporin homologues from the European eel (Anguilla anguilla): effects of seawater acclimation and cortiso treatment on renal expression. Biol. Cell 97, 615-627.

Martinez, A. S., Cutler, C. P., Wilson, G. D., Phillips, C., Hazon, N. and Cramb, G. (2005b). Regulation of expression of two aquaporin homologs in the intestine of the European eel: effects of seawater acclimation and cortisol treatment. Am. J. Physiol. 288, R1733-R1743.

Martos-Sitcha, J. A., Gregório, S. F., Carvalho, E. S. M., Canario, A. V. M., Power, D. M., Mancera, J. M., Martínez-Rodríguez, G. and Fuentes, J. (2013) AVT is involved in the regulation of ion transport in the intestine of the sea bream (Sparus aurata). Gen. Comp. Endocrinol. 193, 221-228.

Martos-Sitcha, J. A., Fuentes, J., Mancera, J. M. and Martínez-Rodríguez, G. (2014). Variations in the expression of vasotocin and isotocin receptor genes in the gilthead sea bream Sparus aurata during different osmotic challenges. Gen. Comp. Endocrinol. 197, 5-17.

Moon, T. W. and Mommsen, T. P. (1990). Vasoactive peptides and phenylephrine actions in isolated teleost hepatocytes. Am. J. Physiol.-Endocrinol. Metabol. 259 E644-E649.

Mordasini, D., Bustamante, M., Rousselot, M., Martin, P. Y., Hasler, U. and Féraille, E. (2005). Stimulation of $\mathrm{Na}^{+}$transport by AVP is independent of PKA phosphorylation of the Na-K-ATPase in collecting duct principal cells. Am. J. Physiol. 289, F1031-F1039.

Motais, R. and Maetz, J. (1967). [Arginine vasotocin and development of branchial permeability to sodium during the passage of soft water and sea water in flounders]. J. Physiol. 59, 271

Musch, M. W., Orellana, S. A., Kimberg, L. S., Field, M., Halm, D. R., Krasny, E. J., Jr and Frizzell, R. A. (1982). $\mathrm{Na}^{+}-\mathrm{K}^{+}-\mathrm{Cl}^{-}$co-transport in the intestine of a marine teleost. Nature $\mathbf{3 0 0}, \mathbf{3 5 1}-353$

Nielsen, S., Frokiaer, J., Marples, D., Kwon, T. H., Agre, P. and Knepper, M. A. (2002). Aquaporins in the kidney: from molecules to medicine. Physiol. Rev. 82 205-244.

Preston, G. M. and Agre, P. (1991). Isolation of the cDNA for erythrocyte integra membrane protein of 28 kilodaltons: member of an ancient channel family. Proc. Natl. Acad. Sci. USA 88, 11110-11114.

Preston, G. M., Carroll, T. P., Guggino, W. B. and Agre, P. (1992). Appearance of water channels in Xenopus oocytes expressing red cell CHIP28 protein. Science 256, 385-387.

Raldúa, D., Otero, D., Fabra, M. and Cerdá, J. (2008). Differential localization and regulation of two aquaporin-1 homologs in the intestinal epithelia of the marine teleost Sparus aurata. Am. J. Physiol. 294, R993-1003.

Saito, T., Ishikawa, S. E., Sasaki, S., Fujita, N., Fushimi, K., Okada, K., Takeuchi, K., Sakamoto, A., Ookawara, S., Kaneko, T. et al. (1997). Alteration in wate channel AQP-2 by removal of AVP stimulation in collecting duct cells of dehydrated rats. Am. J. Physiol. 272, F183-F191.

Schafer, J. A., Troutman, S. L. and Schlatter, E. (1990). Vasopressin and mineralocorticoid increase apical membrane driving force for $\mathrm{K}^{+}$secretion in rat CCD. Am. J. Physiol. 258, F199-F210.

Schindelin, J., Arganda-Carreras, I., Frise, E., Kaynig, V., Longair, M., Pietzsch, T., Preibisch, S., Rueden, C., Saalfeld, S., Schmid, B. et al. (2012). Fiji: an open-source platform for biological-image analysis. Nat. Methods 9, 676-682.

Sugimoto, T., Saito, M., Mochizuki, S., Watanabe, Y., Hashimoto, S. and Kawashima, H. (1994). Molecular cloning and functional expression of a cDNA encoding the human V1b vasopressin receptor. J. Biol. Chem. 269, 27088-27092.

Tingaud-Sequeira, A., Chauvigné, F., Fabra, M., Lozano, J., Raldúa, D. and Cerdà, J. (2008). Structural and functional divergence of two fish aquaporin-1 water channels following teleost-specific gene duplication. BMC Evol. Biol. 8 259.

Tipsmark, C. K., Sørensen, K. J. and Madsen, S. S. (2010). Aquaporin expression dynamics in osmoregulatory tissues of Atlantic salmon during smoltification and seawater acclimation. J. Exp. Biol. 213, 368-379. 
Tsunoda, S. P., Wiesner, B., Lorenz, D., Rosenthal, W. and Pohl, P. (2004). Aquaporin-1, nothing but a water channel. J. Biol. Chem. 279, 11364-11367.

Wargent, E. T., Burgess, W. J., Laycock, J. F. and Balment, R. J. (1999) Separate receptors mediate oxytocin and vasopressin stimulation of cAMP in rat inner medullary collecting duct cells. Exp. Physiol. 84, 17-25.

Warne, J. M. (2001). Cloning and characterization of an arginine vasotocin receptor from the euryhaline flounder Platichthys flesus. Gen. Comp. Endocrinol. 122, 312-319.

Warne, J. M., Hyodo, S., Harding, K. and Balment, R. J. (2000). Cloning of provasotocin and pro-isotocin cDNAs from the flounder Platichthys flesus; levels of hypothalamic mRNA following acute osmotic challenge. Gen. Comp. Endocrinol. 119, 77-84.
Warne, J. M., Harding, K. E. and Balment, R. J. (2002). Neurohypophysial hormones and renal function in fish and mammals. Comp. Biochem. Physiol. B Biochem. Mol. Biol. 132, 231-237.

Wood, C. M. and Grosell, M. (2012). Independence of net water flux from paracellular permeability in the intestine of Fundulus heteroclitus, a euryhaline teleost. J. Exp. Biol. 215, 508-517.

Yang, B. and Verkman, A. S. (1997). Water and glycerol permeabilities of aquaporins 1-5 and MIP determined quantitatively by expression of epitopetagged constructs in Xenopus oocytes. J. Biol. Chem. 272, 16140-16146.

Zhu, X., Gilbert, S., Birnbaumer, M. and Birnbaumer, L. (1994). Dual signaling potential is common among Gs-coupled receptors and dependent on receptor density. Mol. Pharmacol. 46, 460-469. 